\title{
Nosotros y los otros: diversidad y cuidado de sí y del otro
}

\section{Ourselves and the others: diversity and caring of the self and of each other}

\section{Denise Najmanovich ${ }^{1}$}

RESUMEN: En este trabajo se intenta aprovechar la potencia del cine para gestar encuentros singulares y habilitar el cuidado de sí y del otro desde los encuentros en lugar de aplastarlo bajo los imperativos morales. Hacer lugar a la diversidad supone aceptar la radical singularidad de toda existencia. Para ello es preciso abandonar la moral del juicio con sus valores abstractos para embeberse en el paisaje de la vida. Nuestra cultura se ha organizado desde una perspectiva identitaria y normalizadora que nos lleva a deshabitar la experiencia del encuentro. De ese modo la diversidad se licúa y queda subsumida en la diferencia, capturada por lo normal como patrón de comparación.

Palabras llave: Diversidad; ética; cuidado.

ABSTRACT: In this paper we have worked the idea of taking advantage of the power of the cinema to manage singular encounters and to enable the care of self and of each other in gatherings, without smothering it according to moral imperatives. Making room for diversity presupposes accepting the radical singularity of every existence. In order to do so, we must abandon the moral of the judgment, with its abstract values, and delve into the landscape of life. Our culture has been organized around an identitarian and normalizing perspective, which leads to disabling the experience of the encounter. Diversity,

1. Universidad Nacional de Buenos Aires, Buenos Aires, Argentina. 
therefore, is liquefied and is subsumed in difference, captured by the normal as a pattern of comparison.

KEYWORDS: Diversity; ethics; care of the self.

El cine como campo de experiencia invita al pensamiento vital en lugar de dejarnos prisioneros de las definiciones de manual y su universo de abstracciones. No es la película en sí misma, sino el modo de acercanos a ella, de aprehenderla, y hacerla trabajar. No se trata de empeñarnos en un descuartizamiento analíticosino de habilitar el pensamiento, a partir de una potente experiencia emocional. El film nos permite embebernos en una escena necesariamente compleja que nos afecta de múltiples modos, abriendo así oportunidades inesperadas. Llevo ya muchos años disfrutando de la experiencia compartida de pensar con el cine. El pensamiento que busco promover en mí y en otros no es una mera actividad intelectual, sino la emergencia de un saber vital en el que se entrama lo afectivo, lo sensible, y lo cognitivo. El pensamiento vivo no tiene fronteras, ni sabe de categorías a priori. Funciona por composición, genera conexiones, crea configuraciones. Mientras el raciocinio se rige por marcos teóricos o modas académicas, el pensamiento se despliega desde el deseo y conecta con lo que le es afín, gestando una ética de los encuentros.

Es más fácil recordar que "de cerca nadie es normal”, como bien decían los antimanicomialistas, viendo una película que leyendo un tratado académico. La singularidad de la existencia es algo que sabemos en tanto seres vivos, pero olvidamos, desvalorizamos o negamos porque hemos sido formados en una cultura normalizadora ${ }^{2}$.

Históricamente, la modernidad ha elevado lo "normal" a un lugar privilegiado del imaginario social. Lo convierte en un arquetipo omnipresente para medirnos y modelarnos, pretende fijar los límites de nuestros movimientos, de nuestros deseos, de nuestro comportamiento visceral, de nuestro lenguaje, de nuestra sexualidad. Los ideales normativos son exudados de la actividad de los "expertos". Nacen de sus laboratorios, de sus escaneos, de sus pipetas, de sus tests estadísticos, de sus disquisiciones, y se enseñorean en los manuales, en las escuelas, en las academias, en las fábricas, en los medios y hasta en las plazas.

El concepto de lo "normal" penetra en todas las áreas para indicarnos cuántas veces debemos ir al baño, cómo deben ser nuestros orgasmos, cuál es la indumentaria

2. Quienes aún no haWWn sospechado de la inextricable relación entre el estado moderno y la estadística, este es un buen momento para comenzar a hacerlo. 
que corresponde llevar a la escuela. Se va haciendo carne a través de la educación sentimental, que a través del bolero indica cómo debe ser una mujer: "soñadora, coqueta y ardiente, debe darse al amor con frenético ardor... para ser una mujer". El refrán popular refuerza el mandato cuando sentencia que "mujer que sabe latín no tiene marido ni llega a buen fin". Se impone una imagen de la familia modelo, indicadores de salud corporal y mental (así, normalmente divididos), sin necesidad de altares ni de recurrir a la magia, con el poco glamoroso procedimiento de estandarización cultural.

"El normal" es el héroe gris de cientos de manuales, opúsculos y academias. Es el galán que arranca los suspiros de infinidad de señoritas que desean "una casa pequeña, con un jardín al frente con primorosas madreselvas”( HIKMET, 1981, p.45). O es la Dama soñada por un sinfín de hombres que esperan de la vida un "hogar dulce hogar" con comedor reluciente donde deglutir el plato típico y saludable de la dieta de moda para una vida sana. Con el tiempo las normalidades cambian, pero no el ideal de ser normal.

Se usa la palabra normal para decir lo más común -estadísticamente- pero también la cultura nos susurra al oído que el normal es excelente, es lo que todos deberíamos ser.

¿Por qué abundar sobre el normal cuando hablamos de diversidades? ¿Por qué hacerlo cuando estamos hablando del cine y pensando el cuidado de sí y del otro? Porque en nuestra cultura "diferente" y "diverso" se utilizan por lo general como sinónimos. De ese modo la diversidad se licúa y queda subsumida en la diferencia, capturada por lo normal como patrón de comparación. Y, sobre todo porque el cine nos da una oportunidad de salir de los "focos estereotipados" mirar de cerca a los personajes, empatizar con ellos. Es una oportunidad extraordinaria para vivenciar otros mundos y generar nuevas experiencias, muy diferentes a las que surgen de las abstracciones categoriales con sus sistemas de normalización. En el cine (y más en general en el arte) no existen "casos", ni "tipos" sino personas vivas en un territorio, en una situación, personas que nos afectan de un modo que no podemos dominar, conectándonos con la existencia singular en su territorio de vida y no con meras abstracciones o etiquetas. A veces un nazi nos resulta atractivo, y nos da asco un personaje que encarna nuestra propia ideología. Nos resulta entrañable alguien a quién jamás saludaríamos si siguiéramos las convenciones impuestas, y nos encontramos con los lados oscuros de aquellos que en otros contextos llamaríamos camaradas. Paradójicamente, la ficción nos da la oportunidad de encontrarnos con la vida de un modo más intenso y afín con nuestra experiencia que lo que nos da la teoría. 
Sin embargo, los modos de categorizar en que hemos sido entrenados siguen siendo un obstáculo a la hora de pensar esas experiencias, de hacer lugar a eso nuevo que se produjo, de expresarlo con potencia. Por eso es preciso construir espacios dialógicos, en lo que podamos revisar los saberes instituidos y abrir oportunidades para lo que aún no ha sido pensado y también para lo que ha sido desvalorizado o deslegitimado. Es por eso que para hacer lugar a la diversidad resulta crucial comenzar por distinguirla de la diferencia que es una noción anclada en el modelo de normalización.

\section{DIVERSIDAD Y DIFERENCIA}

¿Qué espacios de pensamiento se abren cuando rechazamos la pretendida sinonimia entre "diversidad" y "diferencia"? ¿Qué nueva circunvolución se activa en nosotros, qué senderos se bifurcan en nuestro saber? ¿Qué otros modos de vida se hacen posibles?

La "diferencia” es un régimen de variación de la norma. En cambio la diversidad remite a la variedad que no se deja subsumir en un patrón. Lo diverso nos lleva hacia a otra dimensión del orden y también a una manera distinta de ordenar. La "diferencia" siempre se dice respecto de algo, la diversidad no nace de un régimen determinado de comparación. La diferencia puede organizarse en sistema, la diversidad nos abre la puerta para ir a jugar.

"Diferencia" es un término de la familia de "diferir" que está relacionado con el desacuerdo, la discrepancia, y la discordia y que, paradójicamente, sólo pueden existir si hay un plano de concordancia, un patrón común, un sistema de referencias único. La diversidad, en cambio, pertenece a la familia de divergir, derivado del latín «divergere», derivado de «vergere», éste es variante de «vertere» que significa: girar, invertir. Según el Diccionario de María Moliner, lo diverso se relaciona con la aversión, la diversión y la subversión, y también con la travesura y la travesía, la adversidad y el versificar, entre otros.

Las diferencias se expresan en relación a una unidad, admiten una vara común, pertenecen a un mismo ordenamiento. La diversidad, simplemente diverge, existe en otro nivel de experiencia, no admite incluirse en un sistema de medidas. Es por eso que mientras algunos se divierten otros sienten aversión. Los cultores de lo claro y distinto como sinónimo de lo único y verdadero sólo pueden admitir diferencias, desviaciones de la norma y errores pero no aceptan jamás la diversidad, ni la radical "otredad del otro", ni su singularidad. 
El cosmos entendido como uni/verso no admite lo di/verso, por eso es preciso pensar, dejar de lado la vara de medir y habilitar el espíritu lúdico para poder acoger la diversidad de experiencias y sus tensiones. Sólo así podremos comprender la diversidad con los otros y también en nosotros. Este último aspecto es crucial porque la normalización nos ha impuesto una concepción identitaria del "yo" que nada tiene que ver con la versátil variedad que somos cada uno de nosotros.

$\mathrm{Al}$ mismo tiempo, es preciso saber que así como el cine nos invita a una experiencia de lo singular, del encuentro vivo con el otro, también puede ser un modo de promover arquetipos y sostener estereotipos. Goebbels fue un verdadero maestro de la tipificación así como Bergman nos dio la oportunidad de encontrarnos con lo singular. Más aún, nunca es la película en sí la que porta sus sentidos, siempre somos nosotros en nuestro modo de ser afectados y en nuestra potencia de pensarla los que los producimos.

"Yo SOY MI PROPIA MUJER"

Con ese título encontraremos tanto un trabajo de docuficción dirigido por Rosa von Praunheim, como una obra de teatro de Doug Wright, en ambos casos sobre la vida de Charlotte von Mahlsdorf. Ella fue conocida casi exclusivamente por ese nombre aunque nació y fue inscripta como Lothar Berfelde. Vivió casi toda su vida adulta vestida de mujer, cambió su nombre y eligió como apellido el nombre de la ciudad donde nació.

Quiero compartir con ustedes una escena que me resultó profundamente conmovedora. Lothar -que aún no se había bautizado a sí mismo como Charlotte- está probándose vestidos de su tía, que aunque tiene muchos, viste casi siempre con ropas masculinas. Ella entra y lo mira atentamente, sin juzgar. Sólo le pregunta si le gusta vestir esas prendas. Él, ruborizado y tímido, asiente. Y ella le responde: "La naturaleza se ha permitido una broma con nosotros". Su tono amoroso y pleno de sentido del humor así como la aceptación radical que expresa, marca un punto de inflexión en la vida de Lothar que empieza a devenir primero en Lottchen y luego en Charlotte.

A diferencia de la actitud dominante en nuestra cultura que tiende a concebir como natural sólo lo que se ajusta a los patrones normalizados, y concibe como antinatural, desviado y patológico a todo lo demás, el director propone otra mirada: la que se escapa del juicio y conecta desde la vida. 
En ningún momento el espectador siente el dedo acusador, la tabla de los mandamientos ni el deseo de diagnosticar, propios de la moral del juicio. Todo se presenta de modo natural, aun lo más disruptivo (cuando Lothar mata al padre, o cuando ya como Charlotte se deja azotar por su pareja en el juego sexual). El director no juzga, no impone valores, narra una vida. Su estética no es la de la moral y el juicio sino la de la ética y el pensamiento vital.

Permítanme un pequeño rodeo para entender estas distinciones entre la perspectiva del juicio moral y la mirada ética del pensamiento vital. El juzgar nace de la ilusión de trascendencia, de la creencia en valores eternos, de los afectos de la dominación. En cambio el pensamiento vital brota de los encuentros, de las composiciones que se forman en ellos y nuestra comprensión activa de los vínculos en los que participamos. Para ejercerlo en plenitud es preciso deshacerse de los preconceptos, habitar la experiencia desde su singularidad y también comprender nuestra pertenencia a la naturaleza, y a partir de ello darnos cuenta que no existe, ni puede existir, nada "antinatural". La naturaleza no se rige por leyes, ni por ideales, es profundamente activa y productiva generándose a sí misma y de todos nosotros como parte de ella. En ella toda existencia es singular. Las clasificaciones surgen de un proceso de abstracción, varían con el tiempo, y son muy distintas en cada cultura.

LotharLotchenCharlotte no es un caso de una clase, es una persona singular. Ninguna categoría la representa (porque no estamos pensando desde la representación, sino desde la potencia de existir de cada quien). A lo largo de la película la vamos conociendo, nos familiarizamos con ella. Podemos llegar a entender, o aceptar sin comprender, incluso aquellos gustos que pueden resultarnos más extravagantes (pero que no por eso son menos naturales) porque toda la película está exenta de calificación y moralina. Todo lo que ha ocurrido en la vida de Charlotte es presentado con naturalidad y gracia. Incluso la relación sadomasoquista con una de sus parejas más importantes y el gusto que comparte con otro de sus amantes de fotografiarse vestida de mujer y en actitud muy femenina con los genitales masculinos al viento. Sólo cuando dejamos de preguntarnos si está bien o mal, si es correcto o no, si es decente o indecente, que son juicios a priori, basados en valores abstractos, puede comenzar a desplegarse el pensamiento vital: la comprensión del modo de existencia a partir de lo que nos produce en el encuentro singular.

Otra escena de la película puede ayudarnos a entrar en el clima narrativo y acercarnos más a la ética de la aceptación y la comprensión. Bajo una fina llovizna, Charlotte está con su paraguas frente a la tumba de su madre. Sin dramatismo alguno, 
delicadamente nos cuenta que cuando él tenía treinta años, ella le dijo: Tesoro, ya estás en edad de casarte. Y su respuesta fue: Mamá, Yo soy mi propia mujer. Su madre, sin pedir más explicaciones, contestó: Sí, entiendo. Y si quieres vivir así, está bien.

Charlotte se presenta como Charlotte. Si alguien indaga sobre su género o sexualidad ella no tiene inconveniente en situarse en la categoría travesti aclarando que jamás ha tenido problema con sus genitales, que no desea cambiarlos como los "transexuales".

El sistema del juicio etiqueta e identifica. Organiza la experiencia según unos casilleros prefijados al efecto. Instituye pertenencias y sentencia desviaciones. Sin embargo, no es lo mismo pertenecer a un grupo denominado travesti, que "ser" un travesti. El modelo identitario de la cultura supone una esencia inmutable, una identidad fija y definida dentro de un modelo categorial estable y estanco. La vida, sin embargo, es híbrida, mutante, sus límites pueden ser robustos, pero jamás absolutos, muchas veces son tenues y sutiles y siempre están cambiando. El pensamiento vivo busca comprender las singularidades, sus modos de componer, las afinidades que crean los vínculos, las formas en que cambian, los afectos que los mueven, los efectos que producen. No concibe identidades homogéneas y fijas, sino pertenencias heterogéneas y móviles.

La diversidad se sustrae al pensamiento identitario, circula por otros andariveles. Charlotte no tiene una identidad (nadie la tiene), porque las identidades pertenecen a las clasificaciones y no a la existencia. Lo diverso sólo puede pensarse desde la singularidad radical de la existencia.

Charlotte no es travesti, Charlotte no usa la ropa que esperaríamos que usara según nuestras categorías instituidas. Podemos llamarla travesti porque es una categoría vigente, pero no corresponde a su "ser", sino a nuestro modo de clasificar. Tampoco sigue los cánones que confinan el deseo sexual en el "otro" sexo, como si sólo existieran dos. Charlotte no es un caso de una población, ni un elemento de una clase (ya sea travesti, homosexual, o masoquista), es alguien singular que se viste de mujer, le gustan los hombres y experimenta con el sexo, que logra resistir la violencia nazi, la represión del régimen comunista, y a los neonazis de la Alemania reunificada. Una restauradora experta en antigüedades, una curadora de museo, una activista de la diversidad, entre otras muchísimas hebras que tejen la trama de su vida. Y no es que ella no encaje en la tipificación, es que la vida resiste, supera, y erosiona toda clasificación. Una vez más: de cerca nadie es normal...y tampoco desviado. De cerca, como se nos presentan los personajes en el cine, todos somos singulares, lo que no impide que tengamos muchísimos rasgos comunes. 
UNA ESTÉTICA HÍbRIDA QUE AYUdA A SALIR DE LOS MOLDES.

Un motivo central para elegir esta película es la estética con la que fue filmada que al mezclar la "ficción documental" con la "ficción ficcional" nos permite también cuestionarnos las pretensiones "realistas" del género documental, para darnos cuenta que es tan sólo un modo peculiar de la ficción. Todo "documental" (como todo documento) es una creación llevada a cabo en un lenguaje, desde una perspectiva, con un modo específico de abordaje. Sin embargo, nuestra cultura nos ha hecho creer que es capaz de representar fielmente la realidad (entendida como un mundo independiente del sujeto), cuando lo único que puede hacer es presentar una mirada, necesariamente situada, encarnada, específica. La imaginación técnica está presente en toda producción cinematográfica: los realizadores disponen lo que han de enfocar y de qué modo, cómo utilizar el sonido, y qué ritmo darle al film. Cómo hacer el montaje, qué descartar, dónde empalmar.

El documental es el género más "peligroso" porque encarna la pretensión realista de nuestra cultura objetivista. Sivan y Brauman, en un excelente texto donde reflexionan sobre su film El especialista (documental de su autoría sobre el juicio a Eichmann), sostienen que la verdad "de todo film, no se encuentra en una inconcebible absorción de lo real, sino en una reconstrucción cuya estructura y criterios de elección deben ser explicitados" (BRAUMAN; SIVAN, 2000, p.92).

El "docuficción" expone lo que el documental deja en la sombra, en él vemos a Charlotte instruir a los artistas sobre cómo componer su personaje y desarrollar las escenas. Así nos da la oportunidad de cuestionar el modelo representacionalista que es el marco conceptual sobre el que se ha forjado la ilusión del "normal" y la trampa de la "diferencia". Charlotte es tan diferente como cada uno de nosotros, todos somos diversos, lo que no quita que seamos semejantes.

"Pensar con el cine" no es lo mismo que "pensar el cine", pero es imposible no dar cuenta de algunos aspectos cruciales de la experiencia cinematográfica. En particular de la ilusión de representar la realidad (ilusión que se da tanto en el documental como en buena parte de la producción ficcional, aunque de modos diferentes). Al mismo tiempo, es importante ser conscientes que aun cuando después reconozcamos el artificio, en el momento de ver la película nos embebemos en la escena y en la narración. De ese modo, la potencia del film reside precisamente en la ilusión de ser parte de eso que está ocurriendo. A la inversa de la película de 
Woody Allen en que el actor sale de la película, por lo general somos nosotros los que entramos en ella.

El imaginar es una experiencia del ser humano, moviliza los afectos y tiene profundos efectos. Si salimos de las dicotomías de manual que oponen la "realidad" a la "imaginación", y el "documental" a la "ficción", para ingresar al mundo paradójico de la vida, podremos aprovechar a fondo la potencia del cine en el aprendizaje personal y colectivo.

La película no representa la vida de Charlotte, pero hace presente una narración, y esta cobra sentido para cada quién según su modo de conectar, de dejarse afectar, en relación a su propia historia, las resonancias y conexiones que sea capaz de habilitar, la potencia con la que pueda desplegar su pensar. Para mí Charlotte es una mujer con una inmensa capacidad de sobreponerse a los obstáculos, de desplegar el propio deseo, de unirse a otros para resistir y construir, una amante de la vida capaz de sobrevivir a los tiempos más oscuros, aceptando su propia diversidad y la de los demás. También una mujer que ha matado a su padre en defensa propia y que ha tenido que resistir y consentir para sobrevivir a los más aterradores regímenes.

\section{Ética DEL ENCUENTRO Y EL CUIDAdo}

Una película no puede ser pensada en el vacío, porque pensar es una actividad vital, es habitar la experiencia y conectarla con otras para poder comprender los vínculos. Para esa deliciosa, pero energéticamente muy costosa tarea, no hay manuales, cada quien seguirá el camino de sus asociaciones, de aquello que le es afín, de lo que tiene sentido en su propia vida. Pero aun cuando el pensamiento es singular (nadie puede pensar por mí) tiene mucho en común con el de los demás, lo que nos permite crear paisajes compartidos y aprender unos de otros.

Intento relacionarme con Charlotte desde la aceptación radical de la diversidad y la legitimidad de todo modo de existencia. Busco la comprensión para expandir nuestras posibilidades convivenciales y con ellas nuestra potencia de existir. En este camino es imprescindible desprenderse de las concepciones identitarias de nuestra cultura occidental colonialista, donde la persecución y desvalorización (cuando no represión y eliminación) de lo diverso es "normal" (y esencial para la normalización). Dado que esta concepción es tomada por verdadera y universal, resulta útil dar cuenta de su historicidad y parcialidad. 
Antes de las imposiciones morales cristianas que llegaron con la conquista y colonización, los nativos americanos reconocían cinco géneros: Mujer, hombre, mujer de dos espíritus, hombre de dos espíritus, y transgénero (BRAYBOY, 2016, p. xi).

No moralizaban la naturaleza sino que buscaban comprenderla. En la misma sintonía, muchos exponentes del movimiento "queer" contemporáneo están dejando atrás las perspectivas identitarias. Como sostiene Beatriz Preciado(2009, p. 17): "lo 'queer' no es una identidad más en el folklore multicultural, sino una posición de crítica atenta a los procesos de exclusión y de marginalización que genera toda ficción identitaria”.

Ahora bien, comprender su historicidad, su carácter imaginario, no alcanza para disipar el hechizo. Es preciso un trabajo personal y colectivo que nos permita pasar de una cultura del control y la obediencia, del deber ser y la norma, a una del encuentro y la composición vital capaz de albergar la diversidad.

$\mathrm{Y}$ es aquí donde el cine o el teatro pueden ser un obstáculo (cuando estereotipan) o una oportunidad maravillosa (cuando nos permiten la conexión vital y singular), para gestar modos de convivencia capaces de albergar la diversidad y promover el cuidado mutuo.

Para comprender la diferencia entre el estereotipo, ligado siempre a la abstracción y al juicio, y la singularidad de la vida, haré un contrapunto entre la película de von Praunheim y la obra de teatro de Doug Wright. En la película hubo un trabajo conjunto entre Charlotte, los actores, el director. No hay ningún momento en que yo haya sentido una mirada juzgadora, más bien al contrario, todo se desliza con naturalidad y gracia. Sólo una escena me resulto extraña por lo poco creíble: un encuentro de Charlotte con los agentes de la STASI (la policía del régimen). Ellos la interrogan y ella elude elegantemente sus preguntas, intentan sobornarla pero sin éxito, insisten en pedirle datos de los miembros de las organizaciones gay que la visitan. Y ella responde que no sabe ni nombres ni direcciones, como mucho el nombre de pila. ¿Cómo puede ser eso? le preguntan incrédulos los espías. Ella responde impertérrita: por razones de seguridad, como en la época de los nazis.

La escena transcurre en exteriores, por la noche, iluminada por un foco distante. Me resultaría más verosímil si fuera un sueño, pero el director no da pistas al respecto. Habiendo sido yo misma militante y atravesado varias dictaduras en mi país, me resulta del todo imposible esa provocación a los agentes de la Stasi, aun cuando Charlotte la pronuncia en tono suavísimo como si los estuviera invitando a tomar el té, en lugar de estar comparando el régimen comunista con el nazi. Jamás sabré si el director ha 
creído que las cosas sucedieran así (él mismo es un activo militante de los derechos gay), si eligió esa atmósfera extraña para promover la sospecha, o simplemente no le importaba si las cosas habían ocurrido así o de otro modo. Tampoco importa mucho, es una escena entre tantas, una hebra en la densa trama de la vida de Charlotte.

Para Doug Wright la relación con la STASI se convirtió en el centro y núcleo de su relación con Charlotte y lo llevó a cambiar completamente la escritura de la pieza teatral. Es importante comprender su reacción para apreciar las diferencias éticas y estéticas de las dos obras, y así distinguir entre la moral juzgadora unida inextricablemente al deber ser, y la ética de pensamiento vital, el encuentro y el cuidado.

Wright empezó a escribir la obra muy enamorado del personaje (noten que digo el personaje y no la persona). El adoraba a su heroína, que no es lo mismo que querer a una persona. En "Retrato de un enigma" la introducción reflexiva que escribió para la publicación de la obra de teatro nos dice:Había mantenido durante mucho tiempo un interés casual en la historia gay, y Charlotte parecía un verdadero tesoro. (... ) su heroísmo tranquilo - el mantenimiento de un inquebrantable sentido de sí misma durante esos momentos represivos - podría ser una gran ayuda para los hombres y mujeres homosexuales en todas partes. En una época donde los políticos siguen rutinariamente condenando la homosexualidad en las noticias de la noche $y$ “ maricón” sigue siendo el más punzante de todos los epítetos del recreo, la insistencia tenaz de Charlotte en su propia sexualidad podría resultar francamente curativa, un antídoto para una comunidad demasiado a menudo asediado por la condena pública e internalizado auto-odio. Ella era una auténtica heroína gay (WRIGHT, 2004, p.xi) ${ }^{3}$.

Él se proponía escribir un panegírico, una narración edificante con una heroína sin fisuras, pero en el transcurso de la investigación la imagen que se había forjado se deterioró. El idolatraba a la militante a la que suponía de una determinación y coraje absolutos. Deseaba escribir un relato épico de su vida, pero no pudo porque en el transcurso de su investigación se abrieron los archivos de la STASI que la presentaban como colaboradora del régimen comunista. Como suele suceder con los ídolos y los héroes, sólo basta una mancha a la pureza de su imagen para que caigan en desgracia.

Mi modo de ser afectada ha sido muy distinto. La Charlotte de Praunheim me resulta entrañable, empatizo con ella, siento comunidad en la diversidad. Sé por experiencia vital que bajo los regímenes de terror sólo se sobrevive haciendo compromisos, y se vive resistiendo, y que no existen el uno sin el otro. Como

3. Traducción de la autora. 
magníficamente ha expresado Inés Hercovich (2000, p.137): "Bajo amenaza de muerte, se trastocan los significados de las acciones y los códigos habituales ya no sirven. Bajo amenaza de muerte, consentir es resistir". Por supuesto que haymuy diversos modosde consentir para sobrevivir y de resistir para vivir, pero bajo unrégimen de terror no es posible salvar la vida a base de discursos de una sola pieza, hay que camuflarse, simular, aceptarpequeñas -y a vecesmayores- componendas. Más aun, cuando más poderosa es laresistencia, más necesario es dar algunasseñales de conformidadconelrégimen.

En su excelente libro Esther y Ruzia, MashaGessen narra la vida de sus dos abuelas bajo los regímenes nazi y soviético. Allí nos cuenta que sus dos abuelas fueron mujeres con conciencia, lo cual significó que, en algunos momentos cruciales de sus vidas, ambas intentaron hallar la manera de firmar una paz honrosa con el sistema para luego darse cuenta de que "...pasaron años y vidas enteras buscando un compromiso decente, para acabar descubriendo, antes o después, que no existía" (GESSEN, 2006, p.19). Es que lo que llamamos "decente" nace de una moral sostenida en abstracto, pero cambia radicalmente, incluso antagónicamente, bajo la amenaza de muerte o en un régimen dictatorial. Y eso vale tanto para los que se oponen al régimen como para sus esbirros, que también precisan de la mentira y la falsificación. Lo sabe incluso Wright, cuando sostiene: "Uno no puede buscar 'hechos' en los archivos de la STASI. Esos agentes tenían cuotas que cubrir, supervisores a los que impresionar. Los reportes fueron modificados todo el tiempo. Un documento contradice a otro" (WRIGHT, 2004, p xi). ${ }^{4}$

En la película alemana $L a$ vida de los otros tenemos otra mirada sobre la policía secreta del régimen comunista. El protagonista es un agente al que mandan a espiar a un escritor y su mujer. En ella, como en muchísimas obras de ficción y trabajos de investigación, nos encontramos con los muchos modos que la gente utilizó para resistir, sabiendo que eran permanentemente espiados, "informando" para desinformar, entregando algo que ya sabían que la policía conocía.

MashaGessen, relata el caso de "los novios de una poetisa que resultaron ser informantes, pero en sus informes regulares a la policía secreta la habían retratado como una ávida estalinista- lo que, en definitiva, la libró de ser encarcelada"(GESSEN, 2006, p.19)Y cómo "tras reconstruir varios historiales similares, el historiador dejó de confiar en cualquiera de las informaciones encontradas, pues era imposible

4. Traducción de la autora. 
descifrar la relación entre aquellos documentos y las vidas de las personas a quienes concernían" (p.20).

Como he comentado ya, Wright era plenamente consciente de las dificultades para establecer qué había ocurrido sólo a partir de los documentos de la STASI. Sin embargo, después de que los encontró nada vuelve a ser lo mismo. Incapaz de comprender que nadie sobrevive al terror siguiendo nobles principios (siempre abstractos), sino por el contario encarnando la paradoja y la contradicción para burlar al régimen: consintiendo para sobrevivir, resistiendo para vivir. Una vez perdida su ilusión se sintió defraudado, burlado, herido, lo que lo llevó a una parálisis en su escritura. Ya no puede narrar las hazañas de la militante sin fisuras. En su proyecto épico no entra una Charlotte compleja, contradictoria ...viva, sólo había lugar para la heroína. La frustración se disipa cuando encuentra la forma de cambiar radicalmente su obra: de una épica triunfante se transforma en la historia de una duda, la del propio autor, ya que él mismo se vuelve personaje. Incapaz de tolerar la pérdida de una ilusión hace de la relación entre Charlotte y la policía secreta prácticamente el centro de la obra. Charlotte, como persona compleja, necesariamente contradictoria, se desvanece. Y, aun cuando él no tiene certeza alguna respecto a su presunta traición, toda la obra es una especie de juicio y ya Kafka nos enseño de qué modo perverso el juicio mismo es la sentencia (KAFKA, 1983).

No puedo aquí profundizar en la obra, tampoco quiero hacerlo. Lo que me importa destacar es esta diferencia crucial entre personaje y persona, entre el héroe y el ser vivo, entre los principios morales y las necesidades vitales. Entre los arquetipos abstractos y la complejidad de la vida.

No sé, y no creo que nadie sepa, qué fue lo que pasó entre Charlotte y la STASI. A veces ni siquiera los protagonistas son conscientes de todas las formas de resistir $\mathrm{y}$ consentir que tienen que poner en acto para sobrevivir y vivir. Pero considero penoso reducir la vida a una cuestión, cualquiera que sea. Más aún, cuando esa reducción se debe a las ilusiones y desilusiones que la idolatría crea.

Es por eso que me sentido infinitamente más afín con la película que con la obra de teatro. Aun cuando en el film el tema se toca de un modo inverosímil para mí, todo lo que se expresa nace de un encuentro potenciador entre el director, los actores y Charlotte y así se transmite a la audiencia. La obra de Wright deja un regusto amargo, quedamos empantanados en el juicio, y nos perdemos de la enorme potencia de esta persona contradictoria e intensa que hasta es su propia mujer. 
El cuidado de sí y del otro sólo puede nacer de los encuentros vitales, nunca de los ideales. Cuando olvidamos al ser vivo complejo para buscar la pureza del ideal, abandonamos toda posibilidad de cuidado. Porque cuidar no es "hacer el bien", sino potenciarnos mutuamente, "hacer sinergia". El otro de la moral sólo es legítimo cuando se atiene a la escala de valores vigentes. El otro de la ética es un ser vivo con el que se establece un vínculo en el que nos afectamos mutuamente y puede potenciarnos o despotenciarnos. Nada está dado a priori, ni en abstracto, todo fluye al ritmo de los encuentros y de la comprensión que tenemos de nuestra existencia necesariamente común.

Los héroes, como los príncipes azules y las mujeres maravilla, son seres imaginarios, y cómo tales son idolatrados mientras dura la ilusión o vilipendiados cuando esta se termina. Sólo los seres vivos pueden ser cuidados o descuidados, y eso no dependerá de una ilusión sino de los afectos que se generan en los encuentros. Habitualmente cuidamos a quienes queremos y descuidamos a los que odiamos o nos son indiferentes. Pero en la medida en que podemos pensar y comprender la necesidad y la legitimidad de todos los modos de vida y la pertenencia común a la naturaleza, podemos cultivar en nosotros una capacidad de cuidar que no dependa de la circunstancia actual. Esa disponibilidad al cuidado no es una cuestión moral, no depende de principios abstractos, no está sujeta a desilusión porque no nace de una ilusión, nace del pensamiento vital, de la comprensión de que toda existencia es coexistencia, de que toda vida es convivencia. Desde la ética del encuentro, cuidar a otro no es lo que hago por su bien, sino lo que hacemos para potenciar nuestra vida común.

\section{REFERÊNCIAS}

BRAUMAN, R; SIVAN, E. Elogio de la desobediencia. México: Fondo de Cultura Económica, 2000. BRAYBOY, D. Two spirits, one heart, five genders. Indian Country Today. Native \& American Indian

News, culture, music, art and more. September 7, 2017. Media Network.com. - ICTMN.com. Disponible em: <https://newsmaven.io/indiancountrytoday/archive/two-spirits-one-heartfive-genders-9UH_xnbf VEWQHWkjNnorQQ>. Acesso em: 23 jan. 2016.

GESSEN, M. Esther y Ruzya. Barcelona: Península, 2006.

HERCOVICH, I. La violación sexual: Cuando consentir es resistir. Ediciones de mujeres/ISIS internacional, Santiago de Chile, n. 29, p. 135-148, ago. 2000.

HIKMET, N. Antología poética. Madrid: Visor, 1981.

KAFKA, F. Obras completas. Trad. Joan Bosch Estrada. Madrid: Teorema, 1983. 
PRECIADO, B. "Queer": Historia de una palabra. Parole de Queer.. Valencia, abr.-jun. 2009.

p. 14. Disponible en: <https://www.scribd.com/fullscreen/79992238?access_key=key2164jqncgcgodxmcd 3 jr $>$. Acesso em: 12 mar. 2016.

WRIGHT, D. I am my own wife: Studies for a play about the life of Charlotte von Mahlsdorf. New York: Faber and Faber, 2004 .

\section{SOBRE A AUTORA}

Denise Najmanovich é Epistemóloga e Bioquímica (Universidad de Buenos Aires, Argentina). Tem Mestrado em Metodología de la investigación (Universidad Belgrano, Argentina) e Doutorado em Epistemologia (Pontifícia Universidade Católica de São Paulo). É docente de Psicología Educacional na Universidad de Buenos Aires e de Comunicación Estratégica na Universidad Nacional de Rosario. Trabalha em temáticas relacionadas a enfoques de complexidade, novos paradigmas e pensamento contemporâneo na educação, subjetividade, vínculos e redes. E-mail: denisenajmanovich@gmail.com.

Página web: www.denisenajmanovich.com.ar.

Recebido em 27 de janeiro de 2018 e aprovado em 22 de março de 2018. 